\title{
Las meigas: la transformación de un estigma en recurso patrimonial
}

\section{Galician Witches: the transformation of a stigma in a heritage resource}

\author{
Guadalupe Jiménez-Esquinas \\ Instituto de Ciencias del Patrimonio (Incipit). \\ CSIC, Santiago de Compostela
}

\section{RESUMEN}

Este artículo plantea una reflexión en torno a los procesos de patrimonialización de las meigas gallegas teniendo en cuenta su marginalización y exclusión en el pasado y su actual transformación y reinterpretación como recurso social. Para abordar este proceso de cambio han de tenerse en cuenta diversos factores contextuales tanto globales como locales que tienen que ver con cambios socioeconómicos y la explosión del mercado turístico. Pero, más allá de una lógica económica, el patrimonio es recurso que puede servir al cambio social a través de la recuperación de la historia de estas mujeres que fueron estigmatizadas desde una mirada misógina y excluyente.

Palabras clave: Brujas, Patrimonio, Recurso social, Estigma, Género, Galicia.

\section{SUMMARY}

This article reflects on the heritage formation processes of Galician witches considering their marginalization and exclusion in the past and its current transformation and reinterpretation as a social resource. To address this process of change it must be taken into account different contextual factors related to socioeconomic changes and the tourism market. But, beyond its economic purpose, heritage is a resource that can produce social changes through the recovery of witches' history; the history of women who were stigmatized from a misogynist and exclusive point of view.

Key words: Witches, Heritage, Social Resource, Stigma, Gender, Galicia.

La mujer, hija del pecado, madre de pecadores, tiene en su ser pecado y penitencia. Si además tiene poder, la expiación ha de ser suma. [...] Y pese a los exorcismos, la mujer los comete porque existe, porque, dado que existe, hace que otros los cometan (Valcárcel 1991: 85). 


\section{INTRODUCCIÓN}

La existencia de las meigas ${ }^{1}$ en el imaginario, en las expresiones ${ }^{2}$, en las prácticas cotidianas e incluso en el propio paisaje cultural gallego a través de su toponimia ha sido recogida en la obra de algunos autores (Alonso Romero 1999; Caro Baroja 1961; García Pérez 2010; Lisón Tolosana 2004; Mariño Ferro 2006). Si atendemos a la imagen social que se manejaba de las meigas a finales de la Edad Media y principios de la Edad Moderna, y hasta bien entrado el siglo XVIII, nos encontraremos con una historia de persecución y estigmatización social. Esta imagen polisémica y ambivalente de la meiga en el pasado puede resultar paradójica si la comparamos con la neutra o positiva que se maneja en la actualidad en sus usos patrimoniales. La resignificación de esta figura femenina se inscribe en complejos procesos de patrimonialización minimizando el contenido negativo con el que simbólicamente se identificaba y desgajándola de su dramática historia.

En este artículo planteo una profundización en su historia y una reflexión teórica en torno a la figura de la meiga, fruto del extrañamiento (Velasco y Díaz de Rada 2009: 215-217) por la actual inversión en su carga simbólica y su reconversión en un recurso turístico. La reconversión de las meigas gallegas en un recurso social nos permite hablar de la interacción entre acciones globales y locales (Aguilar, Merino y Migens 2003; Robertson 2000), de relaciones de poder y del papel de las hegemonías en la construcción del patrimonio, entre otros factores (Frigolé y del Mármol 2008: 191). El análisis de los factores glocales (Robertson 2000) que tienen incidencia en la reconversión de las meigas, como son la terciarización en el sector productivo y la búsqueda de nuevos recursos (Aguilar, Merino y Migens 2003; Freire 2009), así como la aplicación de una perspectiva de género permiten, además de conocer algunas claves de los procesos de patrimonialización, un ejercicio comprometido para rescatar una porción de la historia de estas mujeres olvidadas por la historia oficial.

El análisis del patrimonio cultural como una construcción social (Prats 2004: 2038) susceptible de reformularse, resignificarse y legitimarse en función de las circunstancias locales y de las dinámicas de la globalización (Salazar 2005: 137) es un punto de partida valioso para promover la reflexión social (Cruces 1998; Greenwood 2000). Evidenciar la incidencia, más o menos directa, de una hegemonía social y cultural (Prats 2004: 20) en sus distintas fases, desde la selección de referentes simbólicamente representativos, hasta su activación y la generación de un discurso que los sustente, es un ejercicio comprometido con los distintos agentes implicados con desigual participación en las dinámicas patrimoniales. Algunas de las cuestiones sobre las que se reflexiona en este artículo serán analizadas a partir de la comparación entre la imagen social que se tenía de las brujas gallegas en el pasado, recogida a través del análisis bibliográfico, y la imagen social que se maneja en el contexto actual, ejemplificada a través de las formas iconográficas que se muestran en las páginas web de dos fiestas de Galicia y la representación de las meigas en los souvenirs.

\footnotetext{
${ }^{1}$ Palabra gallega para designar a las brujas y que, según el Diccionario de la Real Academia Española, la opinión vulgar considera que "tiene pacto con el diablo y, por ello, poderes extraordinarios".

${ }^{2}$ Como en la frase popular "Eu non creo nas meigas, pero habelas, hailas".
} 
El ejercicio de crítica patrimonial (Prats 2005; Velasco y Díaz de Rada 2009: 248250) y la perspectiva de género que se aplican en este texto se revelan como imprescindibles para el análisis de la reconversión del estigma de esta figura simbólica femenina en un recurso social (García García 1998), explicitando algunas de las dinámicas que la han sustentado y han permitido difuminar la parte negativa de su pasado histórico. A partir de ambas perspectivas, la aproximación se puede realizar desde la distribución desigual del poder y los capitales simbólicos que subyace, tanto en la mirada misógina y excluyente con que se estigmatizaba a estas mujeres en el pasado, como en su positivización, recuperación y revitalización en el presente como recurso económico y posible recurso social.

\section{LA FIGURA DE LA MEIGA EN EL PASADO}

La reconstrucción histórica de la imagen social de las meigas a través del análisis bibliográfico es un reto ante la gran producción a que ha dado lugar en distintos momentos históricos y desde diferentes perspectivas (Alonso Romero 1999; Caro Baroja 1961; Ehrenreich y English 1988; Federici 2010; Fernández Álvarez 2002; Ginzburg 2003; Kramer y Sprenger 2005; Levack 2006; Lisón Tolosana 2004; López Ibor 1976; Mannarelli 1999; Mariño Ferro 2006). Sin embargo, poniendo en relación a las protagonistas de la historia con su propio contexto social y analizando tanto sus características sociodemográficas como otros datos de las conocidas como "cacerías de brujas" (Levack 2006), son relativamente escasas las obras clásicas que abordan estos hechos sociales desde una perspectiva de género ${ }^{3}$. El análisis desde la perspectiva de género es una ruptura epistemológica fundamental para tratar, tanto el androcentrismo del contexto de las meigas, como en las investigaciones que no tuvieron en cuenta las desigualdades en las relaciones de género y otorgaron carta de naturaleza a los modelos de masculinidad y feminidad, a las desigualdades y jerarquías entre unos y otras (Moncó 2011: 27).

Los grandes movimientos de persecución y procesos en contra de las brujas en el contexto europeo comenzaron en el Medievo tardío y se prolongaron en la Edad Moderna hasta el S. XVII e incluso hasta el XVIII en el caso español (Lisón Tolosana 2004: 9-50). La magnitud de estos procesos es mal conocida, dada la propia imprecisión de las acusaciones y la falta de registros oficiales. Algunos autores establecen en 90.000 el número de persecuciones en Europa y de 45.000 el de ejecuciones de brujas (Levack 2006: 23), aunque hay otros que defienden que el número real de muertes puede contarse por millones. La mayoría de las procesadas fueron mujeres, en torno a un $85 \%$ de las ejecutadas contando entre viejas, jóvenes y niñas (Ehrenreich y English 1988: 12) y los escasos hombres eran acusados por sus características "femeninas" (Opitz-Belakhal 2009: 97).

\footnotetext{
${ }^{3}$ Algunas de las obras manejadas hacen referencia al carácter misógino de la cacería de brujas (Caro Baroja 1961: 33, 55, 112; Fernández Álvarez, 2002), pero su análisis desde una perspectiva de género como factor determinante para que las cacerías de brujas se llevasen a cabo ha sido principalmente realizado por Ehrenreich y English (1988) y Federici (2010). Gracias a los estudios feministas han aumentado en los últimos tiempos las aproximaciones a la figura de las brujas desde esta perspectiva.
} 
En el caso español algunos autores (Caro Baroja 1961: 221; Lisón Tolosana 2004; Trevor-Roper 1969: 99) argumentan que la Inquisición procedió de modo "prudente y mesurado" pero que, al margen de esta institución, la "justicia" era impartida por las autoridades civiles y por los poderes no formales. La propaganda que se llevó a cabo contra las brujas tuvo una gran repercusión en la sociedad, que hizo propia la persecución y sin la cual la campaña de terror no hubiera tenido tanto éxito (Trevor-Roper 1969: 115). Para el caso gallego las cifras recogidas por Lisón Tolosana son sólo la punta del iceberg del fenómeno (ibid.: 9-50) pudiéndose contar sólo 112 casos de magia, brujería y hechicería entre 1565 y 1683. Es interesante analizar el perfil social de los implicados: 82 mujeres frente a 20 hombres, escasa presencia de menores de 30 años e incremento a partir de los 50 años, siendo llamativo el número de mayores de 80 años en un contexto donde esta edad no sería muy común. En cuanto a las profesiones, hay un elevado número de viudas, solteras, mendigas y parteras, y, en ausencia de este dato, el autor asume que el resto son esposas de labradores (ibid: 11-12).

Los datos manejados muestran que entre las meigas gallegas abundaban las mujeres que en su contexto subvertían los mandatos que la estructura social les tenía destinados. La relación de su exclusión, persecución y muerte por razones de género, y su segregación, tanto a nivel estructural como en la vida cotidiana, hacen pensar en una auténtica campaña feminicida (Lagarde y de los Ríos 2006: 12). Las viudas y las monjas eran las únicas mujeres que podían salir de su estatus de dependencia respecto a la unidad familiar, se convertían en cabeza de familia y no debían obediencia a un hombre proveedor (Fernández Álvarez 2002: 125-127). Las viudas, las solteras y las sanadoras, que manejaban cierta cuota de conocimiento y poder en su servicio a la población campesina, se alejaban del modelo social de hembras domésticas y reproductoras, y eran vistas como peligrosas por la ausencia de la figura central masculina del padre-marido-sacerdote, protagonista de la vida social y referencia de neutralidad. Las mujeres, y especialmente las brujas, eran consideradas la alteridad, "las otras", las opuestas al paradigma de lo humano y sus virtudes en un sistema androcéntrico (Moncó 2011: 19).

Esta visión intensamente androcéntrica encuentra su reflejo en tratados como el Maellus maleficarum o "martillo de las brujas" que, a partir de su publicación en 1486 por los reverendos Kramer y Sprenger, fue durante tres siglos un recurso fundamental que la Inquisición puso en manos de sacerdotes, magistrados y jueces católicos y protestantes en su combate contra la brujería (Kramer y Sprenger 2005). Este código legal consagrado a los delitos de brujería acusa directamente a las mujeres por su "naturaleza" pecadora, su debilidad mental, exceso de afecto y su propensión al vicio (ibid: 113-124), oponiéndose estructuralmente a la bondad masculina, su fortaleza, don para la justicia y su menor tendencia natural al pecado.

El análisis de todo el entramado de instituciones, legislaciones y los esfuerzos dedicados a la caza de brujas muestra que esta persecución no surgió espontáneamente entre la población rural, sino que fue una campaña de terror desencadenada por la clase dominante (Ehrenreich y English 1988: 13). A pesar de las teorías que atribuyen las cazas de brujas a explosiones de histeria colectiva (López Ibor 1976: 2628) e incluso a intoxicaciones alimentarias generalizadas debidas al cornezuelo del centeno, el contexto histórico en el que se desarrolló la quema de brujas sugiere al- 
gunas otras motivaciones que podrían tener las iglesias, tanto católica como la incipiente protestante, y los estados por la amenaza política, religiosa y sexual que suponía la brujería. De hecho las persecuciones más encarnizadas de las brujas suelen coincidir, tanto geográfica como cronológicamente, con períodos de gran agitación social. Las cacerías de brujas en ocasiones se fusionaron como un único fenómeno, con las insurrecciones campesinas que cuestionaron el sistema feudal (Barros Guimeráns 1990) ${ }^{4}$, el nacimiento del capitalismo (Federici 2010)5 , el auge del protestantismo, las oleadas de herejías que recorrían Europa $^{6}$ y la obsesión por combatir el criptojudaismo en España, entre otros factores contextuales (Ehrenreich y English 1988: 12; López Ibor 1979: 9 y 44; Trevor-Roper 1969: 90-192)7.

Las acusaciones de brujería no dependían tanto de sus prácticas, sino de "la mirada social, que excluye de las propias fronteras culturales y simbólicas a todos aquellos que son vistos como extraños" (Prat 2001: 200). Las brujas representaban el mal, la oposición a las virtudes religiosas y femeninas, que consagraban a las mujeres como reducto de la moral, la sacralidad doméstica y la honra (Fernández Álvarez 2002: 120). Simbolizaban todas las inversiones factibles del modelo de mujer virtuosa, piadosa y casta.

Las acusaciones sobre las brujas se cernían sobre sus cuerpos, sus saberes y su reproducción con el fin de controlarlos y tratar de erradicarlos con el uso de la violencia. Eran acusadas principalmente de tener sexualidad, de estar organizadas y de poder obrar sobre la salud, bien con propiedades curativas o con poderes que causaban el mal. La acusación de cometer todo tipo de crímenes y aberraciones sexuales es una obsesión en los tratados sobre brujas, siendo especialmente relevantes las perversiones sexuales que se relatan con todo lujo de detalles en el Martillo de las Brujas (Kramer y Sprenger 2005). En los $s a b b a t b^{8}$, reuniones entre brujas presididas por el demonio, se suponía la práctica de todo tipo de ritos sexuales opuestos a la moral como las orgías, el lesbianismo, la sodomía y el característico beso en el trasero al macho cabrío. La aberración sexual y moral de las brujas también afectaba a su propia fisonomía. La iconografía que ha representado tradicionalmente a las

\footnotetext{
${ }^{4}$ Como lo fueron las Revueltas Irmandiñas en la Galicia del siglo XV, que cuestionaron y subvirtieron el poder de los señores feudales (Barros Guimeráns 1990)

${ }^{5}$ Federici (2010) observa en las persecuciones contra las brujas un interés en romper con las colectividades y las solidaridades campesinas. La exclusión social de las brujas, las persecuciones y las cacerías facilitarían la acumulación capitalista al promover la privatización y la desconfianza entre vecinos, usurpando los bienes comunales a aquellos sectores poblacionales cuya subsistencia era más dependiente de estos recursos.

${ }^{6}$ Algunas de estas herejías tenían tendencias antinatalistas como los cátaros, albingenses, vandois, munsteritas, tuchinos, husitas, bogomilas y anabaptistas, que subvertían los deseos de las élites de superpoblar Europa con mano de obra barata.

${ }^{7}$ Este psiquiatra español en su obra "¿Cómo se fabrica una bruja?", utiliza como explicación al fenómeno de la brujería diversos factores sociales, económicos y religiosos y no solamente como consecuencia de enfermedades mentales. De hecho, el propio título del libro alude a la naturaleza construida de la brujería.

${ }^{8}$ Son interesantes los paralelismos entre los términos aplicados tanto en la brujería como en el judaísmo, así como también en las prácticas que se les atribuían. En este caso la reunión entre brujas lleva el mismo nombre que el día de descanso en la tradición hebraica. Es una muestra de la mezcla entre brujería y criptojudaismo en un contexto histórico donde el colectivo judío representaba la alteridad, la quintaesencia de la perversión y la herejía (Caro Baroja 1961: 134; Trevor-Roper 1969: 110).
} 
brujas $^{9}$, así como sus descripciones redundan en su fealdad, ancianidad, decrepitud, su deformidad, suciedad, desaliño y sus hábitos desordenados, entre los que se incluían el vicio, el alcoholismo y otras adicciones (Caro Baroja 1961: 219). Algunas de las escenas de persecuciones muestran el liderazgo de hombres "expertos" en brujas que muestran su agresividad y virilidad frente a la comunidad, encontrándonos con la "escena vil, repetida una y otra vez en el mundo, en la que el hombre fuerte, sano y joven se encarniza con la mujer vieja, débil y desvalida" (Opitz-Belakhal 2009: 99) ${ }^{10}$. Según los datos de los procesos inquisitoriales (Levack 2006; Lisón Tolosana 2004), la senectud, la viudedad o la soltería, la pobreza y el aislamiento respecto al pueblo eran algunas de las características reales de las mujeres encausadas.

La acusación más incomprensible era la de tener conocimientos prácticos sobre sanación. Las sanadoras, bruxas, sabias, santas, meigas, curandeiras y remedieiras debían de ser las únicas personas que en la época y el contexto rural gallego conocerían las prácticas curativas y, especialmente, en el ámbito obstétrico-ginecológico. La presencia de una sanadora en la localidad ofrecía además independencia frente a la curación médico-científica que ejercían los varones. La iglesia concebía la persecución de las sanadoras como una lucha contra la magia y el empirismo ${ }^{11}$ ya que interferían en la voluntad divina que observaba el sufrimiento como expiación. El Maellus Maleficarum especifica: "Nadie causa mayores daños a la iglesia católica que las comadronas" (Ehrenreich y English 1988: 15), y tanto curanderas como matronas sufrieron una gran campaña de persecuciones y desprestigio que llega hasta la actualidad (Marsá González 2009: 93-94).

En el ámbito gallego las meigas eran figuras ambiguas reconocidas por su bondad o su maldad en función del momento y la persona que las juzgara. A pesar de que contaban con aspectos positivos, la de "curar a las personas" fue la acusación más frecuente en los casos estudiados por Lisón Tolosana (2004: 15). Según este autor esta acusación se veía favorecida por la especial configuración del paisaje rural gallego, disperso y difícilmente comunicado, donde estas mujeres proveían de cuidados a sus vecinos. Y, aunque esta era la figura más extendida, no estaban ausentes las brujas estereotipadas y definidas en los términos del Maellus Maleficarum, las acusaciones entre vecinos, las persecuciones y los ajusticiamientos, tanto entre las meigas "benéficas" como entre las "maléficas", ya que dada la ambivalencia y labilidad de su figura una sola denuncia era suficiente evidencia (Trevor-Roper 1969: 151). Los rumores y habladurías han servido como catalizadores para acusar a los débiles o marginados de la sociedad, pudiéndose interpretar como una consecuencia del temor a que los débiles se venguen de los fuertes (Stewart y Strathern 2008: 5-9).

Las meigas fueron perseguidas por la hegemonía eclesiástica y política, por las autoridades civiles y por los vecinos del pueblo, que se tomaban la justicia por su mano

\footnotetext{
9 Algunos grabados de los Caprichos de Goya son muy ilustrativos, así como ilustraciones clásicas de la literatura infantil, como la bruja de Blancanieves o la Sirenita.

${ }^{10}$ Es el ejemplo narrado en Cartas desde mi celda de Gustavo Adolfo Bécquer donde, describiéndolos como hechos reales sucedidos en 1861, narra la persecución y asesinato de la Tía Casca por los hombres del pueblo.

${ }^{11}$ La eficacia de los remedios empleados por las meigas solían estar basados en la experiencia y buscaban un efecto físico. En contraposición la medicina patrocinada por las iglesias se regía por una actitud pasiva basada en los dogmas y principios religiosos.
} 
por su carácter ambiguo, contaminado, peligroso y fuera de todo orden social (Douglas 1973; Moncó 2011: 159). Las brujas eran temidas porque tenían "poderes" que no les pertenecían por el hecho de ser mujeres y porque podían usarlos en contra de la sociedad, dada la inestabilidad racional que se atribuía a la esencia femenina (Douglas 1973: 148). Las meigas fueron mujeres estigmatizadas socialmente, no tanto por sus prácticas, sino por la mirada misógina y excluyente con que se las veía (Prat 2001).

\section{LA PRODUCCIÓN DEL PATRIMONIO}

Como ya se mencionó en la introducción, si partimos de la estigmatización social con que cargaban las meigas a finales de la Edad Media y principios de la Edad Moderna resulta especialmente llamativo el rescate en exclusiva de su carga simbólica positiva en sus usos patrimoniales actuales. La profundización en la selección de referentes y su posterior activación para su uso patrimonial, minimizando y desgajándolas de su ignominioso pasado, nos habla de las dinámicas locales, las relaciones de poder y del sistema de representaciones. Permite, además de rescatar una porción de la historia de las olvidadas, una aproximación a la relación compleja entre la producción de la localidad y los flujos de globalización, así como visibilizar el papel que desempeñan los procesos de patrimonialización en la construcción de hegemonías (Frigolé y del Mármol 2008: 191).

La inversión simbólica de las meigas se produce en el presente sustentándose en un pasado idealizado. Hay que recordar los movimientos románticos y nacionalistas del S. XIX como inicio de todo un proceso de búsqueda y puesta en valor del pasado, en el que la historia medieval y pre-romana se instituyó como época dorada y definitoria de las nacionalidades y de las tradiciones populares, reinterpretadas en el contexto romántico (Prats 2004: 25-27). La recurrencia a las raíces celtas de Galicia, su percepción como un territorio de difícil acceso que resistió a la cristianización (Trevor-Roper 1969: 107), la persistencia de los rituales paganos celebrados por las meigas y toda una serie de personajes míticos, ofrecieron un punto de legitimación a la propia existencia de Galicia y un punto de construcción frente a las identidades de las demás nacionalidades del territorio español (García García 1998).

Los procesos de valorización de la cultura popular y su consideración como elementos patrimonializables, como bienes colectivos que deben ser conocidos, conservados y transmitidos a generaciones futuras (Ortiz García 2002), comenzaron a desarrollarse cuando el progreso tecnológico e industrial se tornó en una posible amenaza para las formas de vida "tradicionales".

La recurrencia al pasado permite establecer una continuidad histórico-temporal que genera cierto sentido de pertenencia al grupo y una forma de afrontar la globalización y la celeridad de los cambios históricos de la modernidad avanzada. En un contexto globalizado no es extraño que, desde una lógica simbólico-identitaria (Prats 2004: 33 y 46), se recurra a la patrimonialización frente a la homogeneización, no sólo como una estrategia de reflexividad y reproducción social sino también como elemento diferenciador, como un recurso social en un contexto en el que el patrimonio supone una plusvalía (García García 1998). La resignificación y puesta en valor en un contexto de modernidad avanzada o posmodernidad de un referente denostado y 
rechazado en el pasado no obedece solo a una motivación nostálgica o tradicionalista, sino que constituye también una respuesta a factores globales que inciden en las realidades locales (Frigolé y del Mármol 2008: 193). La patrimonialización puede ser entendida, desde una lógica económica, como una nueva industria que añade valor al pasado y se utiliza en el presente. Estos procesos añaden valor a bienes y recursos existentes que, o bien ya no son viables (modos de subsistencia, tecnologías obsoletas, lugares abandonados, etc.), porque nunca fueron rentables económicamente, o bien son inalienables (Kirshenblatt-Gimblett 2001: 45). Las crisis en los sistemas productivos, junto otros factores, como la despoblación de los territorios y la emigración a las ciudades, han provocado profundos cambios en algunos contextos que han observado los recursos patrimoniales y el valor de la diferencia, reorientando sus economías hacia el turismo y el sector de los servicios (Salazar 2005).

En el contexto gallego, que ha sufrido bruscas transformaciones económicas, sociales y culturales en las últimas décadas, la decadencia del sector productivo primario ha inducido algunos trasvases hacia el turismo y los servicios (Prats 2004: 39-55). Este cambio de orientación hacia el sector terciario no ha surgido espontáneamente, sino que ha sido potenciado desde instancias externas (demandas de turismo cultural por parte de sectores urbanitas, marcos supra-nacionales de actuación para el desarrollo económico, fondos europeos para el desarrollo de zonas rurales, etc.) que inciden en este tipo de transformaciones para el "desarrollo rural" (Freire Paz 2009).

Las perspectivas económicas en torno al turismo y los servicios han potenciado las activaciones patrimoniales, entre ellas la de las meigas y la iconografía relacionada con ellas. Su resignificación contemporánea tiene que ver también con otros factores contextuales glocales. Las meigas se suelen relacionar con un pasado de connotaciones paganas, con práctica esotéricas, con la naturaleza salvaje, montañosa y misteriosa, con remedios naturales e incluso con una incipiente muestra de independencia y poder femenino. Estos factores han sido interpretados en un contexto postmoderno donde ganan importancia la búsqueda de la experimentación de lo extraordinario, toda una serie de posturas heterodoxas y nuevos tipos de religiosidad ${ }^{12}$. También se valora positivamente lo salvaje y lo rural como muestra de "originalidad" y "autenticidad", hay un auge de las medicinas alternativas y naturales, así como cierta visibilización del esoterismo. La ruptura con la norma social que planteaban las meigas también ha sido interpretada e idealizada en el contexto actual ${ }^{13}$ como incipientes muestras de feminismo, valorándose especialmente por los feminismos de la diferencia y los ecofeminismos ${ }^{14}$ (Amorós 1998: 85-118).

\footnotetext{
${ }^{12}$ Entre estas nuevas formas de religiosidad hay que contar con el auge de los nuevos paganismos, como los movimientos druídicos y, sobre todo, la religiosidad wicca. Este conjunto de creencias y prácticas neopaganas recuperan rituales medievales del culto de las brujas y defienden la supervivencia de los cultos femeninos a las diosas desde la "antigüedad" hasta la actualidad. Consideran la sensibilidad, la receptividad, la tolerancia, el eclecticismo y el pacifismo como características positivas intrínsecas a la naturaleza femenina (Clover-Jones 2000).

${ }^{13}$ En este sentido hay algunas actividades y actos públicos que recuperan y hacen justicia a la historia de las brujas, teniéndolas en cuenta como mujeres que se sublevaron ante el patriarcado y reconociendo la pervivencia de la brujería en las mujeres.

${ }^{14}$ Estos feminismos afirman positivamente la diferencia sexual para establecer un programa de liberación de las mujeres hacia su auténtica identidad, dejando fuera la referencia al varón. La parti-
} 
Siguiendo a Kirsenblatt-Gimblett (2001: 46), el patrimonio cultural convierte a los lugares en destinos turísticos y el turismo los hace viables. La atracción de post-turistas hacia un determinado destino depende de su adaptación al contexto actual, del ajuste de su oferta de bienes y servicios a los gustos de los sectores urbanos (Salazar 2005). Estos sectores buscan la experimentación de los elementos diferenciadores del lugar y el valor añadido que representa su patrimonio, en una cierta experimentación de la nostalgia y autenticidad que no se percibe en los centros emisores de turistas. El pasado, la naturaleza salvaje, abrupta, indomable y misteriosa se entienden en la actualidad como un conjunto de recursos patrimoniales que pueden representar una mejora económica sin suponer obligadamente una devaluación del entramado social y simbólico que caracteriza a esas sociedades (Ibid.: 137).

No es mi intención demonizar este tipo de recursos ya que, además de la revitalización económica, también cumplen una función de puesta en valor de lo local y favorecen los procesos de patrimonialización. Pero la apariencia de neutralidad de las activaciones patrimoniales no debe ser meramente asumida como tal, ya que suele eludir la diversidad y las dinámicas locales y, por supuesto, obviar los capitales culturales de los grupos subalternos (García Canclini 1999: 18). Así asegura García Canclini que el patrimonio cultural también sirve "como recurso para reproducir las diferencias entre los grupos sociales y la hegemonía", definiendo los sectores dominantes los bienes a ser conservados (Ibid: 18).

Desde el punto de vista que planteo en esta reflexión, la resignificación de las meigas en el contexto actual ha sido impulsada desde una hegemonía social que ha tomado sólo la parte por el todo de los hechos sociales y de la ambigüedad de su figura. La tradicionalización selectiva de estos aspectos bondadosos de las meigas permite olvidar la historia oscura de las olvidadas, rescribiéndose por parte de las élites sociales los testimonios que sus protagonistas no nos pudieron legar; unas élites que hace unos siglos tenían elementos en común con sus perseguidores.

Esta perspectiva no solo olvida a las meigas, sino que no atiende a la complejidad expresiva del concepto de recurso patrimonial (García García 1998: 14). Como recurso social, y no sólo económico, los procesos de patrimonialización deben ir acompañados de un alto grado de participación social donde se promueva la reflexión (Cruces 1998: 84) y se proyecten los distintos puntos de vista y las diferentes historias que conviven en un mismo contexto (Prats 2005: 30-31). Así, el patrimonio local puede tener un alto grado de utilidad, no sólo desde una perspectiva económica, sino también como un instrumento social al servicio de la población, como espacio para la reflexión, la participación e integración de sectores sociales diversos.

cipación en el mundo patriarcal es observada como una pérdida de la identidad femenina. Por otro lado, desde los años ochenta, varios movimientos de mujeres se unieron como sujeto revolucionario ante las grandes catástrofes ecológicas originadas por el varón. El ecofeminismo valora la proximidad de las mujeres con la naturaleza, la centralidad de la reproducción de la vida y la economía de subsistencia. Según el ecofeminismo, el patriarcado es una invención del capitalismo y el colonialismo del varón blanco (Amorós 1998: 85-118). Los feminismos de la diferencia idealizan a las meigas como figuras con características positivas: próximas a la naturaleza, rechazadas por el patriarcado, con prácticas de solidaridad entre mujeres, incipientes ecologistas, etc. 


\section{LA INVERSIÓN SIMBÓLICA DE LAS MEIGAS}

Para ejemplificar la resignificación de la figura femenina de las meigas o el rescate exclusivo de sus aspectos positivos en el contexto actual, este artículo se basa en el análisis de algunos elementos y representaciones iconográficas. La cartelería de eventos e imágenes asociadas, y las webs de algunas fiestas que se celebran en la actualidad en torno a las meigas han sido tomados no en sustitución de un trabajo de campo etnográfico en profundidad, sino como ejemplos concretos para ilustrar la reflexión y para contrastar la desvinculación de la esfera negativa donde históricamente se situaban.

En el caso de las fiestas de San Juan, declaradas Fiesta de Interés Turístico Nacional, su web nos informa de que la Comisión Promotora de la Fiestas comenzó su andadura en 1970 ante la corriente de "dar la espalda a una serie de costumbres y tradiciones que se alejaban de un modernismo ramplón en boga en la época". El objetivo de la comisión promotora fue "rescatar la Noche de San Juan" como fiesta estructurada y provista de señas de identidad, para lo cual se sirvió de "nuevos modos de entender la fiesta o recuperando otros que estaban a punto de caer en el ol-

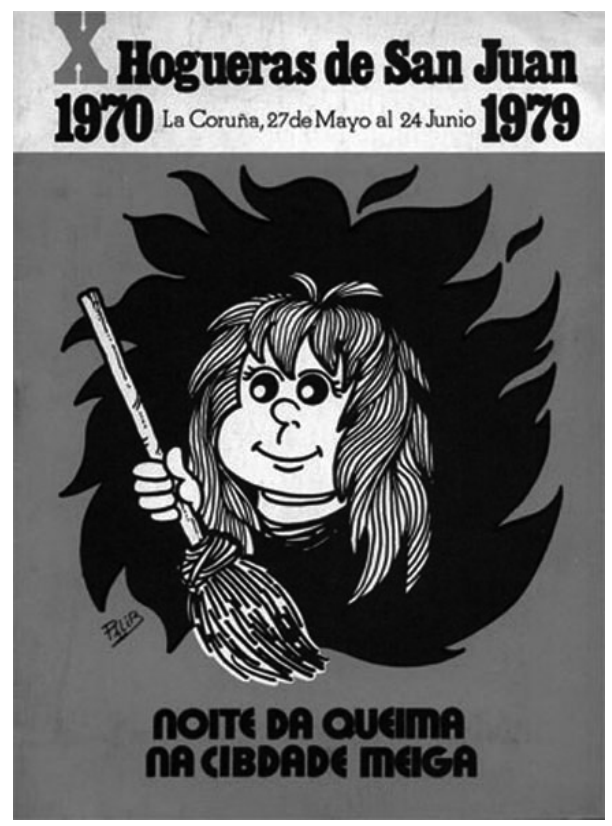

Figura 1.-Cartel de la X celebración de las Hogueras de San Juan en A Coruña. 1979. vido" ${ }^{15}$. Estos argumentos evidencian los procesos de recuperación y reinterpretación del pasado en el contexto actual, sometiendo los rituales a revisiones constantes para su adaptación a los contextos sociales locales de cada momento. Esta festividad es un ejemplo de puesta en valor por parte de agentes sociales de un recurso que, posteriormente, ha sido activado patrimonialmente por los poderes políticos, evidenciando no sólo su función en la reflexión identitaria, sino también la lógica económica que puede existir al impulsar esta fiesta que congrega a miles de personas.

En la cartelería ${ }^{16}$ que anuncia la fiesta se puede apreciar un cambio en la perspectiva que se ofrece de la meiga: desde un protagonismo casi absoluto y una imagen bondadosa e infantil (Fig. 1) hasta la progresiva desaparición de referencia a las meigas y su sustitución por elementos abstractos (Figs. 2 y 3).

En las imágenes manejadas en los anun-

\footnotetext{
${ }^{15}$ Extracto de la sección "Historia" de la página oficial de las Hogueras de San Juan de A Coruña. http://www.hoguerassanjuan.com/index.php?page=2 (Última consulta 20/09/2011).

${ }^{16}$ Imágenes tomadas de la sección Galería de Imágenes de la página oficial de las Hogueras de San Juan de A Coruña. http://www.hoguerassanjuan.com/index.php?page=18 (Última consulta 20/09/2011).
} 


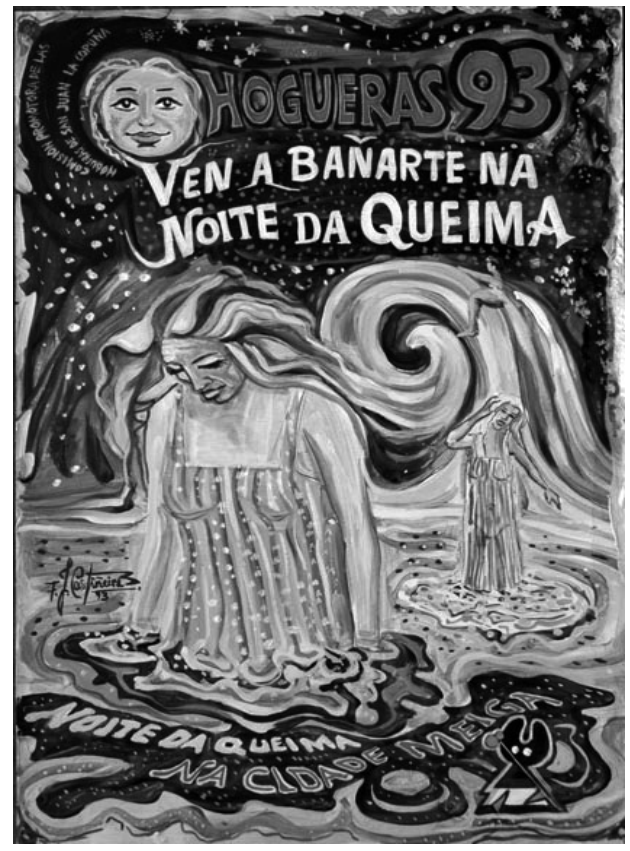

FigurA 2.-Cartel de las Hogueras de San Juan en A Coruña. 1993.

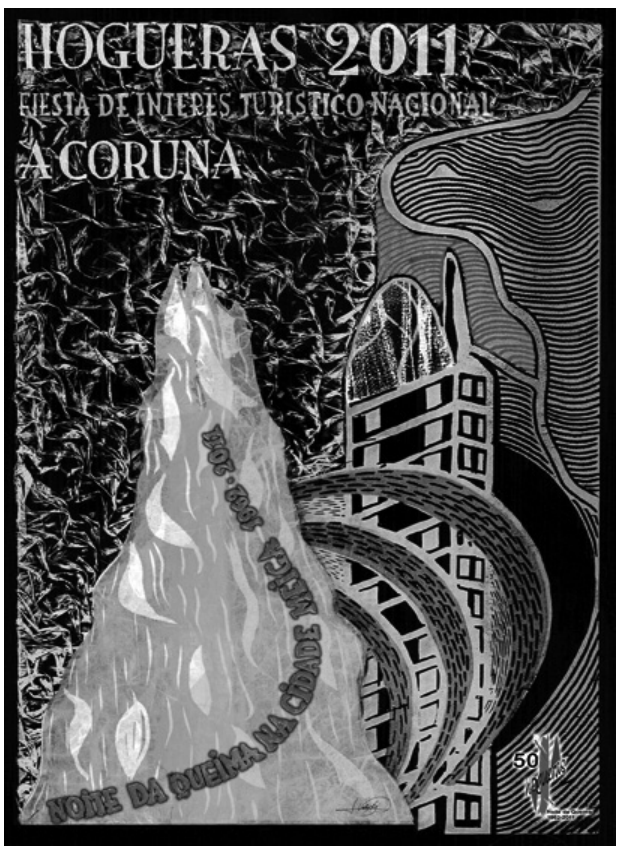

FIGURA 3.-Cartel de las Hogueras de San Juan en A Coruña. 2011.

cios de los primeros años de celebración (Fig. 1 y 2) se aprecia una mayor necesidad de desarticulación de los caracteres negativos de las meigas, con el fin de encontrar un mayor respaldo institucional y consenso social. Esta positivización se torna imprescindible a la hora de establecer la fiesta; las meigas y todo el simbolismo que las rodea como un elemento del pasado que debe ser recuperado y celebrado. En el cartel del año 2011 (Fig. 3) ya se puede apreciar la ausencia de la figura de la meiga, una vez que la fiesta se ha consolidado y cuenta con el respaldo popular.

Dentro del programa de las fiestas de San Juan en A Coruña tiene lugar la Noite da Quema, donde se encienden hogueras y se realizan distintas prácticas en el espacio público en torno a estas, y también la elección de las Meigas y el Aquelarre Poético. Si la iconografía ha invisibilizado las connotaciones negativas con las que históricamente han cargado las meigas, encontramos que también los usos lingüísticos y simbólicos minimizan su historia oscura. La elección de las Meigas en las festividades de San Juan es un concurso donde se elige a las representantes de la ciudad por su belleza. En el Aquelarre Poético se proclama a las meigas elegidas y se lleva a cabo un acto que cuenta con la presencia de poetas que alaban la belleza de la mujer coruñesa. Estas dos celebraciones, seleccionadas entre el amplio programa festivo, se caracterizan por la nueva significación que adquieren las meigas, que ya no son perseguidas por su fealdad, sino por el contrario alabadas por su belleza. Los aquelarres de la Noite das bruxas siguen manteniendo los principios benéficos, son una ocasión para la convivencia vecinal, propician la protección, la renovación y la curación ritual (Lisón Tolosana 2004: 61-77). La inversión del curso normal y lo ordinario, los 
crímenes y aberraciones sexuales cometidos por las meigas han sido sustituidos por actos protocolarios que forman parte del programa festivo oficial.

Entre las imágenes caricaturescas que se han quemado ritualmente en los últimos años durante la noche de San Juan podemos ver algunas representaciones de meigas ${ }^{17}$. Estas gigantescas meigas se presentan sonrientes, bondadosas y benéficas (Fig. 4), cuando no manifiestamente eróticas (Fig. 5), ante los asistentes a la celebración en la que, finalmente y como antaño, terminarán quemando a la bruja a pesar de su renovado aspecto.

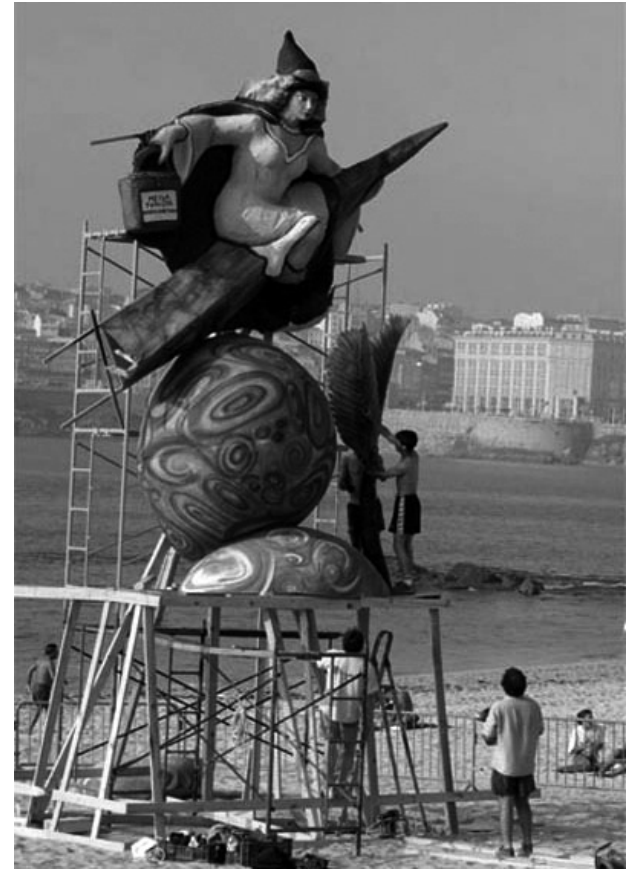

FigurA 4.- -Hoguera de San Juan con figura de meiga. 2001.

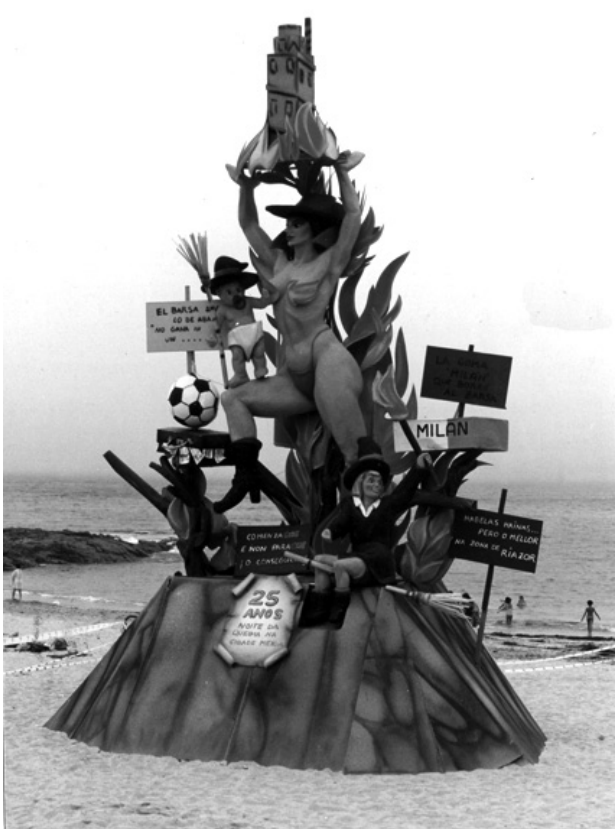

Figura 5.-Hoguera de San Juan con figura de meiga. Celebración de 25 años de la Noite da Quema. 1994.

Por otro lado, la localidad de Ribadavia lleva diez años celebrando su Noite Mei$g a^{18}$. Esta iniciativa festiva surgió, al igual que la festividad de San Juan en A Coruña, de una asociación local. En su web declara que el objetivo de las actividades que desarrollan está en "potenciar e promover o interese que xera esta vila" y que la Noite Meiga "está a comenzar a ser un reclamo turístico que permite, tanto a ós vecinos da comarca do Ribeiro coma ós invitados doutras localidades, gozar e coñecer, se cadra

\footnotetext{
${ }^{17}$ Extraídas de la Galería de Imágenes de la página oficial de las Hogueras de San Juan de A Coruña. http://www.hoguerassanjuan.com/index.php?page=18\&offset=312. (Última consulta 20/09/ 2011).

18 http://www.noitemeiga.com. (Última consulta 26/07/2012).
} 
un pouco máis, o encanto desta vila ademáis de recuperar as raíces celtas da nosa terra". Esta joven asociación pretendía recuperar "alguna festa tradicional" y se centraron en la fiesta del Samaín, relacionada con la festividad celta de final del verano, reactivada en el contexto actual entre otros movimientos por los neo-paganos y druídicos como alternativa a la cristianizada festividad de todos los santos o la norteamericana fiesta de Halloween. Se evidencia en esta celebración orensana el interés por la creación de un recurso social en su función convivencial y dinamizadora de la zona y que a su vez atrajera a vecinos y a turistas a este pueblo, sirviéndose de la reinterpretación de la fiesta céltica y de la historia de las meigas. Esta localidad orensana, que ha visto reducida su población en los últimos años y cuyo sector productivo principal es el de los servicios ${ }^{19}$, también ha desarrollado otros procesos de patrimonialización con recurrencia selectiva al pasado como la celebración de la Festa da Historia y la exaltación del pasado judío de la villa como elemento con valor diferenciador respecto a otras localidades.

Si bien la Noite Meiga de Ribadavia no redunda excesivamente en la positivización de las meigas y abundan las connotaciones más funestas, sí es interesante el ejercicio de rescate de la fiesta del Samaín para legitimar un factor de diferenciación de la comunidad gallega frente a otras del Estado español y la recurrencia a las meigas como un posible elemento articulador de la teoría panceltista defendida por el nacionalismo gallego.

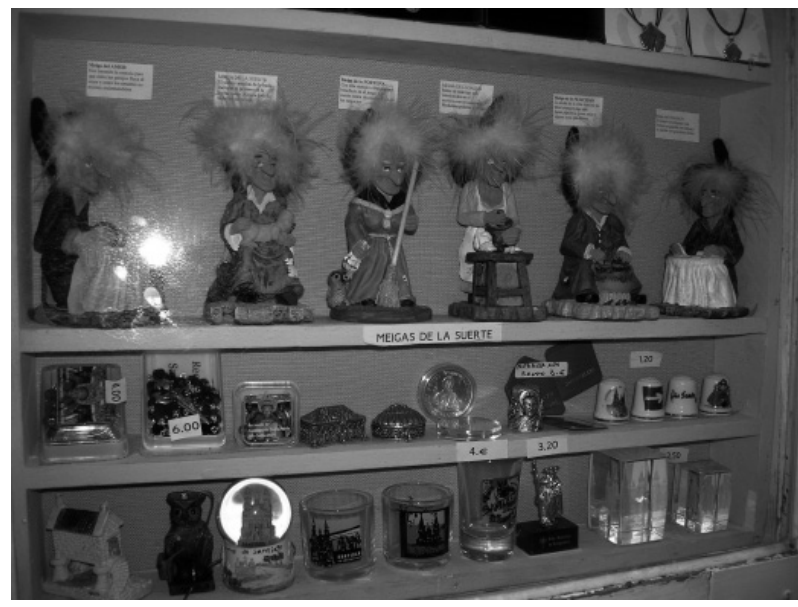

FIGURA 6.-Escaparate de una tienda de souvenirs. Santiago de Compostela, Julio de 2011.

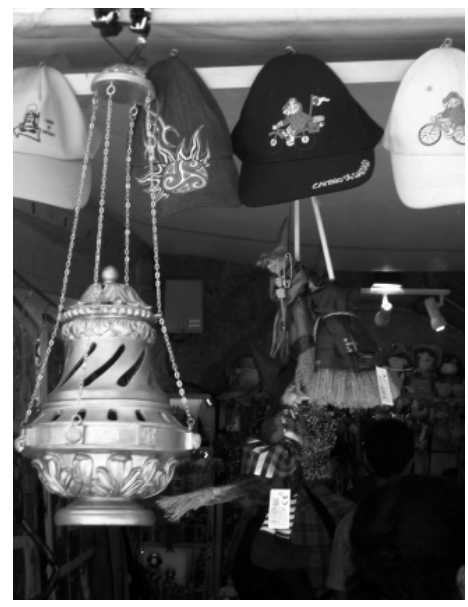

FIGURA 7.-Productos ofrecidos en una tienda de souvenirs. Santiago de Compostela, Julio de 2011.

${ }_{19}$ Datos recogidos en el Instituto Gallego de Estadística. La población ha pasado de 7.050 habitantes en el año 1981 a los 5.490 en los datos de 2010. Es destacable su crecimiento vegetativo negativo de -38 y una edad media de 47.3 años. El mayor número de afiliados a la seguridad social corresponde al sector servicios, seguidos por industria y construcción, ocupando el último puesto la agricultura. 


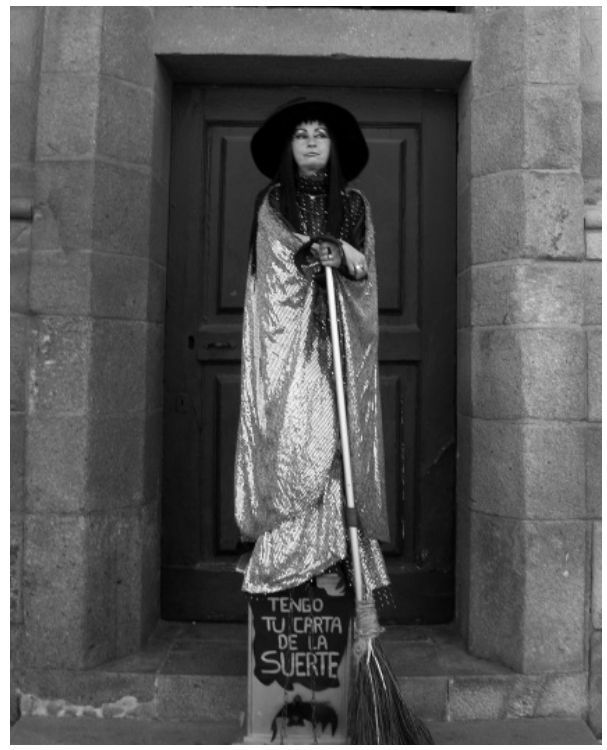

FIgURA 8.-Estatua viviente con atributos de meiga en la Plaza del Obradoiro. Santiago de Compostela, Julio de $2011^{20}$.

Otro ejemplo iconográfico observable en la vía pública que puede ilustrar el desplazamiento simbólico de las meigas desde una esfera negativa a una positiva, siendo reinterpretadas desde el contexto actual, son los souvenirs, publicidad en tiendas y otros productos turísticos. Algunos souvenirs ofrecidos en negocios locales utilizan la imagen de la meiga como representación simbólica de lo que se considera propio del contexto cultural gallego. Esta nueva consideración de las meigas se observa tanto por los turistas y visitantes, que reclaman una reinterpretación del pasado adaptada a sus gustos, como por la población y los poderes locales que observan como posible recurso esta simpática representación, considerándola finalmente algo digno de ser valorado (Novelo 2005: 86).

Esta doble valoración exógena y endógena retroalimenta por un lado el estereotipo de la meiga y por otro lado refuerza su desplazamiento cualitativo. Las meigas que se exponen en los escaparates (Figs. 6 y 7) y en estatuas vivientes (Fig. 8) siguen portando sus calderos, sus harapos, sus gatos, sus escobas y hasta sus cabelleras desaliñadas, según la imagen estereotipada que de ellas se maneja. A pesar de esta representación iconográfica, se acompañan de carteles como "meigas de la suerte", "meigas del amor", "la meiga te entregará tu carta de la suerte", instando a los visitantes a llevarse un producto característico de Galicia que conllevará protección y suerte, asociando también, por tanto, a la imagen actual un atributo antiguo de la bruja: sus poderes curativos y mágicos. La convivencia en un mismo producto de una imagen de la meiga más o menos estereotipada con discursos y prácticas que obvian su negatividad ejemplifica la modificación en su carga simbólica en el contexto actual como se ha pretendido evidenciar a lo largo de este artículo.

\section{CONCLUSIONES Y PROPUESTAS}

Rastreando históricamente la imagen social que se manejaba de las brujas gallegas podemos evidenciar la ambigüedad de su figura, asociándose a la sanación pero, principalmente, unida a toda una serie de valores negativos. El análisis de esta figura femenina y el contexto social donde se enmarcaban las cazas de brujas nos muestra una historia de estigmatización social y persecución, no tanto por lo que estas hacían, sino porque representaban la alteridad desde el punto de vista patriarcal que

\footnotetext{
${ }^{20}$ Fotografías de las figuras 6,7 y 8 realizadas por la autora.
} 
imperaba (Amorós 1998: 21-54). Según el perfil de las ajusticiadas en los procesos contra las brujas podemos deducir que eran mujeres que subvertían el modelo de feminidad establecido, bien por su independencia de una figura masculina, porque se alejaban del modelo social de domesticidad y reproducción, porque manejaban cierta cuota de conocimiento y poder o porque, en definitiva, representaban una amenaza para la clase dominante. Una amenaza política, religiosa y sexual.

Teniendo en cuenta este pasado histórico tan pesimista puede resultar llamativo encontrar en algunas representaciones iconográficas actuales un cambio cualitativo en la carga simbólica de las meigas. En la iconografía con la que he ejemplificado mi argumentación, como la de las fiestas como la noche de San Juan de A Coruña, la Noite Meiga de Ribadavia y los souvenirs expuestos en algunas tiendas, se ofrece una perspectiva positiva de las meigas desvinculándolas de su oscuro pasado. Las meigas se representan como simpáticas figuras, favorecedoras para la suerte y el amor, tienen un aspecto sensual e incluso son sinónimo de belleza y motivo de celebración. Estas mujeres marginalizadas y perseguidas en el pasado han sufrido un proceso de transformación, selección y reinterpretación en el contexto actual transformándose en un recurso social. Las que históricamente fueron estigmatizadas, ahora, gracias a todo un proceso de patrimonialización, parecen simbolizar valores positivos relacionados con los contextos locales.

La resignificación de la iconografía relacionada con las meigas y su uso patrimonial debe inscribirse en un contexto de adaptación local a un ámbito general de globalización. La observación de estas figuras femeninas como potencial recurso social y económico se incluye en procesos más generales, como la creciente terciarización de la producción y la potenciación de una economía centrada en el turismo. En los ámbitos locales la recurrencia a las meigas como símbolo y como recurso social guarda relación con la modificación estructural que ha tenido lugar en las últimas décadas, la decadencia del sector productivo primario, la des-diferenciación del ámbito rural y urbano y los movimientos migratorios ${ }^{21}$. Respecto a la positivización de las meigas, también ha de tenerse en cuenta la nueva orientación de las economías locales hacia las demandas turísticas. En este sentido, la creciente búsqueda de la experimentación de lo extraordinario por parte de los turistas ha reforzado aquellos factores diferenciadores de la homogeneidad que poseen los destinos y los productos turísticos. Las corrientes de revisionismo pagano, el celtismo, las prácticas esotéricas, el misterio, la ruralidad, la utilización de remedios naturales, las posturas religiosas heterodoxas e incluso las muestras de independencia y poder femenino son factores que han ido revalorizándose en el contexto actual. La reinterpretación de la meiga en la actualidad sólo puede entenderse en relación a la positivización de todos los factores contextuales mencionados, permitiendo su transformación en un recurso distinto, "original", "auténtico", adaptado a las tendencias globales, capaz de atraer a turistas y consumidores urbanos.

El dilema se plantea al contemplar la recuperación y celebración e incluso, por qué no decirlo, la mercantilización (Aguilar, Merino y Migens 2003: 171) de hechos sociales tan controvertidos como la marginalización de las mujeres que subvertían el

${ }^{21}$ Los movimientos campo-ciudad posibilitaron que la "ruralidad" no se contemplase como algo tan extraño y sus prácticas, entre ellas las de las meigas, como algo más próximo. 
modelo establecido, su acusación pública y su ejecución. Su positivización y patrimonialización parece reproducir las diferencias del pasado, ya que no se recupera su historia de estigma social, sino su reinterpretación por parte de aquellas hegemonías sociales que la contemplan como un recurso adecuado para las nuevas realidades sociales. La reinterpretación de las meigas vuelve a negar la palabra a las mujeres que fueron marginadas, reescribiendo la historia sin vislumbrar las causas de su persecución, cubriéndolas de un aura positiva que induce al olvido de la historia de las olvidadas.

Si nos valemos del patrimonio como un recurso social no se puede detener su contemplación desde una exclusiva lógica económica. En tanto que recurso social debe permitirse también que sirva al cambio democratizador (Greenwood 2000: 33) a través de un ejercicio de reflexividad dialógica (Cruces 1998: 83), permitiendo la recuperación de distintos puntos de vista y las historias convenientemente ocultadas (Prats 2005: 31). La utilización de la meiga gallega no debe ceñirse exclusivamente a ofrecer nuevos recursos a las economías locales sino que, éticamente, debe contemplarse la participación y la restitución del poder negado a grupos sociales no hegemónicos (García Canclini 1999). Los usos patrimoniales de las meigas deben ir acompañados, además, de una reflexión en torno a esta figura femenina, de la recuperación de su historia "incómoda" (Prats 2005: 26), tanto para comprender su pasado, como para construir un presente y un futuro donde las mujeres no sean estigmatizadas desde una mirada misógina y excluyente.

\section{BIBLIOGRAFÍA CITADA}

Aguilar Criado, E., Merino Baena, D. y M. Migens Fernández, M. 2003. "Cultura, políticas de desarrollo y turismo rural en el ámbito de la globalización". Horizontes Antropológicos 20: 161-183.

Alonso Romero, F. 1999. "Ánimas y brujas de Finisterre, Cornualles e Irlanda". Anuario Brigantino 22: 91-104.

Amorós, C. (dir.). 1998. 10 palabras clave sobre Mujer. Estella (Navarra): Verbo Divino.

Barros Guimeráns, C. 1990. Mentalidad justiciera de los irmandiños, siglo XV. Madrid: Siglo XXI.

Caro Baroja, J. 1961. Las brujas y su mundo. Madrid: Revista de Occidente.

Clover-Jones, M. 2000. Wicca. El manual de la bruja moderna. Barcelona: Océano.

Cruces, F. 1998. "Problemas en torno a la restitución del patrimonio. Una visión desde la antropología". Politica y Sociedad 27: 77-87.

Douglas, M. 1973. Pureza y peligro. Un análisis de los conceptos de contaminación y tabú. Madrid: Siglo XXI.

Ehrenreich, B. y English, D. 1988. Brujas, comadronas y enfermeras, bistoria de las sanadoras. Dolencias y trastornos, politica sexual de la enfermedad. Barcelona: La sal, edicions de les dones.

Federici, S. 2010. Calibán y la bruja. Mujeres, cuerpo y acumulación originaria. Madrid: Traficantes de sueños.

Fernández Álvarez, M. 2002. Casadas, monjas, rameras y brujas. La olvidada historia de la mujer española en el renacimiento. Madrid: Espasa Fórum.

Freire Paz, E. 2009. "(Re)conociendo Mondoñedo. El pasado se proyecta como futuro". Revista de Dialectología y Tradiciones Populares 64 (2): 117-148.

Frigolé Reixach, J. y del Mármol Cartañá, C. 2008. "Los contextos en la producción del patrimonio", en Pereiro, X., Prado, S. y Takenaka, H. (coords.), Patrimoinos culturales: educación e interpretación. Cruzando límites y produciendo alternativas: 187-203. Donostia-San Sebastián: Ankulegi antropologia elkartea. 
García Canclini, N. 1999. "Los usos sociales del Patrimonio Cultural", en Aguilar Criado, E. (coord.), Patrimonio Etnológico. Nuevas perspectivas de estudio : 16-33. Granada: Comares. IAPH.

García García, J. L. 1998. "De la cultura como patrimonio al patrimonio cultural”. Política y Sociedad 27: 9-20.

García Pérez, G. 2010. "Brujas Meigas y afines en el mapa topográfico de España”. Boletín de la Sociedad Ateneísta de Aire Libre 42: 17-21.

Ginzburg, C. 2003. Historia nocturna. Las raíces antropológicas del relato. Barcelona: Ediciones Península.

Greenwood, D. J. 2000. "De la observación a la investigación-acción partipativa: una visión crítica de las prácticas antropológicas". Revista de Antropología Social 9: 27-49.

Kirshenblatt-Gimblett, B. 2001. "La cultura de les destinacions: teoritzar el patrimoni”. Revista d'etnologia de Catalunya 19: 44-61.

Kramer, H. y Sprenger, J. 2005. Maellus Maleficarum. El martillo de los brujos. Barcelona: Círculo Latino.

Lagarde y de los Ríos, M. 2006. "Presentación a la edición en español", en Rusell, D. E. H. y Harmes, R. A. (eds.), Feminicidio: una perspectiva global: 11-14. México: CEIICH-UNAM.

Levack, B. P. 2006. The witch hunt in early modern Europe. London: Pearson books.

Lisón Tolosana, C. 2004. Brujería, estructura social y simbolismo en Galicia. Madrid: Akal.

López Ibor, J. J. 1967. ¿Cómo se fabrica una bruja? Barcelona: Dopesa.

Mannarelli, M. E. 1999. Hechiceras, beatas y expósitas. Mujeres y poder inquisitorial en Lima. Lima: Ediciones del Congreso del Perú.

Mariño Ferro, X. R. 2006. La brujería en Galicia. Vigo: Ediciones Nigra Trea.

Marsá González, V. 2009. “¿Comadronas o brujas? ¿Doctas o enfermas?”. Dossiers Feministes 13: 89102.

Moncó, B. 2011. Antropología del género. Madrid: Editorial Síntesis.

Novelo, V. 2005. "El patrimonio cultural mexicano en la disputa clasista", en Sierra, X.; Rodríguez, C. y Pereiro Pérez, X. (coords.), Patrimonio cultural: politizaciones y mercantilizaciones 85-99. Sevilla: Federación de Asociaciones de Antropología del Estado Español, Fundación El Monte, Asociación Andaluza de Antropología.

Opitz-Belakhal, C. 2009. "Witchcraft Studies from the Perspective of Women's and Gender History. A report on recent research". Magic, Ritual and Witchcraft 4 (1): 90-99.

Ortiz García, C. 2002. "Patrimonio cultural y antropología”. Arevacon 21: 5-9.

Prat, J. 2001. El estigma del extraño. Un ensayo antropológico sobre las sectas religiosas. Barcelona: Ariel.

Prats, L. 2004. Antropología y Patrimonio. Barcelona: Ariel.

Prats, L. 2005. "Concepto y gestión del patrimonio local". Cuadernos de Antropología Social 21: 17-35.

Robertson, R. 2000. "Glocalización: tiempo-espacio y homogeneidad-heterogeneidad". Zona Abierta 92-93: 213-242.

Salazar, N. B. 2005. "Más allá de la Globalización: La "Glocalización" del Turismo". Política y Sociedad 42 (1): 135-149.

Stewart, P. J. y Strathern, A. 2008. Brujería, hechiceria, rumores y habladurias. Madrid: Akal.

Trevor-Roper, H. R. 1969. The European witch-craze of the sixteenth and seventeenth centuries and other essays. Nueva York: Harper Torchbooks.

Valcárcel, A. 1991. Sexo y filosofía. Sobre "mujer" y "poder". Barcelona: Anthropos.

Velasco, H. y Díaz de Rada, Á. 2009. La lógica de la investigación etnográfica. Un modelo de trabajo para etnógrafos de escuela. Madrid: Trotta.

Fecha de recepción: 22 de septiembre de 2011

Fecha de aceptación: 21 de marzo de 2013 